\title{
A IMPORTÂNCIA DO USO DE MATERIAL CONCRETO PARA A APLICAÇÃO DE CONTEÚdOS MATEMÁTICOS
}

\section{ARTIGO ORIGINAL}

SOUZA, Adriane Oliveira de ${ }^{1}$

BEZERRA, Cynara Carmo ${ }^{2}$

SILVA, Clariane Pontes da ${ }^{3}$

SOUZA, Adriane Oliveira de. BEZERRA, Cynara Carmo. SILVA, Clariane Pontes da. A importância do uso de material concreto para a aplicação de conteúdos matemáticos. Revista Científica Multidisciplinar Núcleo do Conhecimento. Ano 05, Ed. 03, Vol. 07, pp. 80-92. Março de 2020. ISSN: 2448-0959

\section{RESUMO}

O artigo visa mostrar a importância da utilização de jogos de matemática como estratégia metodológica para o ensino-aprendizagem de números inteiros no $7^{\circ}$ ano "1" da Escola Municipal Charles Garcia, no município de Parintins/AM. A abordagem utilizada é de natureza qualitativa e a partir dela realizou-se a intervenção necessária para a aplicação do jogo do dominó para que os alunos aprendessem os números inteiros. Trata-se de uma alternativa metodológica. Verificou-se, com base na revisão da literatura, que vários teóricos como D’Ambrósio (2001), Lara (2003), Fleming e Mello (2003), Starepravo (2009), dentre outros, defenderam o uso de jogos como um recurso didático, facilitando, então, o ensino-aprendizagem das operações com números inteiros, pois estimula-se o raciocínio lógico e desperta-se o interesse pela

\footnotetext{
${ }^{1}$ Graduada Em Matemática, Especialização Em Ensino Da Matemática E Física, Mestranda Em Ciência Da Educação.

2 Doutora Em Biotecnologia.

${ }^{3}$ Graduada Em Ciências Biológicas.
} 
disciplina, além de viabilizar a socialização no ambiente escolar ou fora dele. Os resultados mostram que a utilização de jogos nas aulas de Matemática constitui-se como uma estratégia metodológica que auxilia os docentes a tornar as aulas mais dinâmicas e significativas para os alunos.

Palavras-chave: Jogos, ensino-aprendizagem, números Inteiros.

\section{INTRODUÇÃO}

O artigo descreve a utilização de jogos como uma estratégia metodológica para o ensino-aprendizagem de números inteiros com alunos de $7^{\circ}$ ano do Ensino Fundamental II. Teve-se como objetivo averiguar as atividades exploradas na sala de aula pelos professores de Matemática do $7^{\circ}$ ano, construir um material concreto para aplicar no ensino dos conteúdos de Matemática, investigar os pontos fortes e as dificuldades na aplicação das estratégias no ensino da Matemática, refletir sobre como se dá a compreensão dos alunos e mostrar a importância da utilização de jogos como uma estratégia metodológica que contribui para com ensino-aprendizagem de números inteiros. Dessa forma, foi investigada a utilização de jogos no ensino de números inteiros na turma do $7^{\circ}$ ano "1" da Escola Municipal Charles Garcia.

Para a intervenção e realização da atividade, propôs-se o Jogo Dominó para o ensino de números inteiros, e, assim, teve-se como objetivo utilizar e expressar cálculos a partir das operações referentes aos números inteiros e, assim, verificar se houve a fixação do conteúdo após o jogo. Devido ao conjunto dos números inteiros fazer parte do nosso cotidiano e, também, devido à sua compreensão acarretar dificuldades no ensino-aprendizagem, sugeriu-se os jogos educativos como estratégia metodológica. Para fundamentar o trabalho utilizou-se vários autores, dentre eles podemos mencionar: D’ Ambrósio (20011), Lara (2003), Fleming e Mello (2003), Groenwald e Timm (2000), Starepravo (2009), PCN's (1998), Lakatos e Marconi (2007) e Brenelli (1996).

Desse modo, o jogo pode ser um recurso de apoio a ser trabalhado em sala de aula buscando, para isso, a interação entre os conteúdos e o desenvolvimento das 
competências e habilidades dos educandos, tornando-os sujeitos protagonistas de suas aprendizagens. Os Parâmetros Curriculares Nacionais/PCNs (1998, p. 26) afirmam que: "os jogos constituem uma forma interessante de propor problemas, pois permitem que estes sejam apresentados de modo atrativo e favorecem a criatividade na elaboração de estratégias na revolução em busca de soluções". Para facilitar a compreensão do trabalho, inicialmente realizamos uma revisão de literatura, e, na sequência, abordamos os procedimentos metodológicos utilizados. Também realizamos uma discussão acerca dos resultados e trouxemos algumas considerações.

\section{REVISÃO BIBLIOGRÁFICA}

\subsection{A UTILIZAÇÃO DE JOGOS COMO ESTRATÉGIAS METODOLÓGICAS}

Os jogos têm sido utilizado como método de ensino-aprendizagem da Matemática desde a antiguidade. Apesar do seu uso ou desuso na prática docente, vários são os estudos que discorrem sobre a importância dos jogos no processo educacional, pois, em situação de brincadeira ou em contato com jogos, a criança desenvolve sua capacidade de criação e imaginação, buscando, dessa forma, soluções para os problemas que lhe são postos. Para Oliveira (2005, p. 35):

Ensinar Matemática é desenvolver o raciocínio lógico, estimular o pensamento independente, a criatividade e a capacidade de resolver problemas. Nós como educadores matemáticos, devemos procurar alternativas para aumentar a motivação para a aprendizagem, desenvolver a autoconfiança, a organização, a concentração, estimulando a socialização e aumentando as interações do indivíduo com outras pessoas.

Assim sendo, torna-se válido reiterar, segundo o contexto apresentado, que devido ao fato de que a Matemática, desde os primórdios, atua como a base para outras disciplinas que contribuem para estimular novas habilidades, faz-se necessário que a 
criança comece a estudá-la desde o seu primeiro contato com a escola. É sabido, também, que, no decorrer dos anos, o ensino-aprendizagem passou por mudanças metodológicas buscando, portanto, por alternativas que facilitam o trabalho do educador. Essas mudanças se referem aos recursos didáticos e pedagógicos, o que inclui os jogos que, ao serem usados adequadamente, tornam a aprendizagem menos mecânica e mais prazerosa e significativa. A Matemática foi criada pelos povos antigos para resolver os problemas do cotidiano em desde então, faz-se presente na vida das pessoas como uma ferramenta importante de ensino-aprendizagem.

Com o passar dos tempos, a humanidade evoluiu e hoje vivemos em um mundo globalizado no qual as competências e habilidades são exigidas tanto no mercado de trabalho como, também, no convívio social. Para D’Ambrósio (2001, p. 33) é necessário "fazer uma matemática que viva. Se a gente olhar para a história da matemática, ela sempre foi assim: uma representação do ambiente que o sujeito está vivendo, dos problemas que encontra, das coisas que de algum modo provocam uma necessidade de reflexão maior". Dentre uma diversidade de estratégias metodológicas que surgiram ao longo da história estão os jogos educativos que possuem fundamentação teórica, pois são úteis, ao professor, no processo de avaliação do ensino-aprendizagem. De acordo com os Parâmetros Curriculares Nacionais - PCN (1998, p. 47).

As atividades de jogos permitem ao professor analisar e avaliar os seguintes aspectos: Compreensão: facilidade de entender o processo do jogo assim como o autocontrole e o respeito a si próprio; facilidade: possibilidade de construir uma estratégia vencedora; Possibilidade de descrição: capacidade de comunicar o procedimento seguindo e da maneira que atuar; estratégia utilizada: capacidade de comparar as previsões ou hipóteses.

Conforme afirmam Flemming e Mello (2003, p.22), "é importante que os jogos estejam inseridos em um plano de aula bem estruturado, com uma sequência didática que promova a interação entre os objetos de estudo e as estratégias de jogo". Seguindo este raciocínio, acredita-se que a partir de um conjunto de estratégias os jogos 
poderão trazer benefícios ao desenvolvimento escolar dos alunos do $7^{\circ}$ ano "1" da Escola Municipal Charles Garcia. Ao utilizar os jogos como estratégia metodológica, visando, então, a aprendizagem dos alunos, é importante que o professor, como um dos agentes responsáveis pela educação escolar, esteja motivado em mudar a realidade do ensino-aprendizagem, e, assim, para que haja resultado, faz-se necessário que os alunos sejam instigados e desafiados para aprender.

Nesse sentido, é importante ressaltar, neste artigo, segundo Lara (2003) que o jogo educativo pode facilitar, quando bem aplicado e desenvolvido em sala de aula, o processo de ensino-aprendizagem, pois além de atuar como um ótimo recurso didático, ou seja, como uma estratégia de ensino comprovadamente efetiva pelos cientistas da educação, é um rico instrumento para a construção do conhecimento. Nesse esfera, a autora nos orienta que a inclusão de jogos na educação deve ser trabalhada desde cedo com crianças, pois é quando começam a desenvolver seu raciocínio lógico, e, então, o professor deve propor atividades escolares lúdicas, diversificadas, planejadas e desenvolvidas, considerando, sobretudo, as formas de pensar e proceder de cada aluno.

\subsection{A UTILIZAÇÃO DE JOGOS NO ENSINO DE NÚMEROS INTEIROS}

Os matemáticos, na época do Renascimento, sentiram a necessidade de criar um novo tipo de número a partir do qual poderiam indicar e representar o ganho ou perda dessas quantidades. Daí foi constituído o conjunto dos Números Inteiros com a reunião do conjunto dos Números Naturais, o conjunto dos números opostos dos Números Naturais e o zero, representado pela letra Z. De acordo com os Paramentos Curriculares Nacionais - PCN (1988, p. 97).

A análise da evolução história dos números negativos mostra que por muito tempo não houve necessidade de pensar em números negativos e por isso a concepção desses números representou para o homem um grande desafio. O uso dos números negativos é atribuídos aos chineses e aos hindus, que conceberam símbolos para as faltas e diferenças (dividas). A adoção do zero teve um papel-chave na construção dos 
inteiros, possibilitando operar com grandezas negativas, mudando o caráter de zero nada para zero origem, favorecendo, assim, a ideia de grandeza opostas ou simétricas.

A evolução dos números ocorreu de acordo com as necessidades da humanidade, e, assim, os números inteiros foram os primeiros a serem utilizados com o objetivo de contar elementos existentes no contexto histórico no qual se encontravam:

Como tudo na vida, os números negativos originaram-se da necessidade. Eles surgiram para expressamos restos e diferenças de determinadas qualidades. No entanto, só foram aceitos mediante uma aplicação pragmática com o cálculo, a oposição e também resolução de problemas de Álgebra, sendo que até Diófanes (350 a 250 d.C.) considerando o Pai da Álgebra, revelam uma apatia no tocante aos números negativo (PCN, 1988, p. 97).

Embora o conjunto dos números inteiros esteja inserido em diversas situações do dia a dia, costumamos vivenciar dificuldades apresentadas pelos alunos, principalmente em relação à operações que envolvem sinais opostos. Porém, com o uso adequado de jogos, eles, frequentemente, podem contribuir para com a aprendizagem de operações que envolvem sinais. Existem jogos que podem ser utilizados como estratégias metodológicas para o ensino-aprendizagem de números inteiros, e, por isso, a escolha do jogo é importante, devendo, o professor, buscar, portanto, o envolvimento da turma a partir de atividades lúdicas que promovam momentos de socialização e interação. Groenwald e Timm (2000, p. 21) afirmam que:

A aprendizagem através dos jogos, como dominó, palavras cruzadas, memorias e outros, permite que o aluno faça de aprendizagem um processo interessante e até divertido. Para isso, ele devem ser utilizados ocasionalmente para sanar as lacunas que se produzem na atividade escolar diária. Nesse sentido, verificamos que há três aspectos que por si só justificam a incorporação do jogo nas aulas: o caráter lúdico, 
desenvolvimentos de técnicas intelectuais e a formação de relação sociais.

Nessa perspectiva, são vários os benefícios que englobam o ensino-aprendizagem dos alunos por meio da utilização de jogos como estratégia metodológica, porém o professor deve ser criterioso ao escolher o jogo a ser aplicado em sala de aula, como, por exemplo, o jogo dominó para o ensino de números inteiros é bastante recomendado. Ainda na visão de Groenwald e Timm (2000, p. 25): "é importante que sejam estipuladas regras para o jogos a serem trabalhados em sala, par desenvolver o pensamento logico, pois a aplicação sistemáticas das regras encaminha a deduções". Sendo assim, os jogos poderão ser uma atividade cuja utilização como estratégia metodológica é bastante fundamental para ajudar os educandos na construção da sua afetividade bem como para ampliar sua linguagem e seus conhecimentos matemáticos.

\subsection{O DOMINÓ DOS NÚMEROS INTEIROS COMO ESTRATÉGIA METODOLÓGICA PARA O ENSINO-APRENDIZAGEM DA MATEMÁTICA}

O jogo educativo tem um papel importante no ensino-aprendizagem, como, por exemplo, despertar no aluno o interesse bem como o gostar de aprender. Dentre os jogos disponíveis para o estudo da Matemática optamos por trabalhar com o jogo Dominó dos números inteiros, uma vez que tem como objetivo utilizar e expressar cálculos das operações referentes aos números inteiros e verificar a fixação do conteúdo de maneira divertida e rápida de se calcular. Starepravo (2009, p. 20-21), comenta:

Se conseguirmos compreender o papel que os jogos exercem na aprendizagem de matemática, poderemos usá-los como instrumento importantes, tornando-os parte integrante de nossas aulas de matemática. Mas devemos estar atentos para que eles realmente constituam desafios. Para isso, devemos propor jogos nos quais as 
crianças usem estratégias próprias e não simplesmente apliquem técnicas ensinadas anteriormente.

Nesse sentido, é relevante que saibamos em que nível de desenvolvimento o aluno se encontra para podermos selecionar as atividades e os jogos que iremos propor em sala de aula de acordo com as suas especificidades.

\section{METODOLOGIA}

\subsection{TIPO DE PESQUISA}

A abordagem adotada para a elaboração deste trabalho foi a pesquisa qualitativa que, segundo os autores Moreira e Caleffe (2008, p. 73) "explora as características dos indivíduos e cenários que não podem ser descritos numericamente, sendo o dado frequentemente verbal e colocado pela observação, descrição e gravação". Foi realizada uma pesquisa de campo, que, na visão de Lakatos e Marconi (1996, p. 75): "é a pesquisa em que se observa e coleta os dados diretamente no próprio local em que se deu o fato em estudo, caracterizando-se pelo contato com o mesmo, sem interferência do pesquisador", pois os dados são observados e coletados espontaneamente. Foi realizada na sala de aula e teve-se como objetivo verificar a utilização de jogos como estratégia metodológica no ensino-aprendizagem de números inteiros. Portanto, pesquisas de natureza qualitativa e de abordagem fenomenológica explicam o objeto de estudo de forma mais profunda, analisando, para isso, o todo de um procedimento para alcançar os aspectos mais significantes da realidade vivenciada.

\subsection{TÉCNICAS E SUJEITO DA PESQUISA}

Os sujeitos da pesquisa foram os alunos do $7^{\circ}$ ano "1" do Ensino Fundamental II da Escola Municipal Charles Garcia, no Município de Parintins/AM. Foi com a participação desses sujeitos que se realizou a intervenção a partir da aplicação do jogo Dominó para o ensino de números inteiros assim como questionários. Após a intervenção, foi realizada a análise dos dados, que, por sua vez, ofereceu subsídios 
para verificar se o objetivo foi alcançado, e, em seguida, elaborou-se as considerações. As técnicas utilizadas se constituíram de observações. Lakatos e Marconi (2005, p. 192), argumentam que "a observação ajuda o pesquisador a identificar e obter provas a respeito de objetivos sobre os quais os indivíduos não têm consciência, mas que orientam seu comportamento".

Diante do contexto analisado e investigado, foram realizadas observações em sala de aula com o objetivo de conhecer as principais dificuldades que os alunos do Ensino Fundamental II apresentavam em relação ao aprendizado de números inteiros. Uma outra abordagem se deu por meio dos questionários, que, para Lakatos e Marconi (2008, p. 203): é "um instrumento de coleta de dados, constituído por uma série ordenada de perguntas, que devem ser respondidas por escrito, compostas com perguntas abertas, objetivando as argumentações interpretações dos resultados envolvidos". Na interpretação dos dados será considerado o número de vezes que os entrevistados escreveram a mesma ideia sobre o determinado questionamento.

\section{RESULTADOS E DISCUSSÃO}

A partir dos resultados da pesquisa, que se desenvolveu na forma de intervenção, observou-se que existem diversos trabalhos direcionados para os jogos educativos como estratégias metodológicas para auxiliar o processo ensino aprendizagem dos números inteiros, visto que servem para construir conhecimento e atuam como ingredientes motivadores nas aulas de Matemática.

Outro motivo para a introdução de jogos nas aulas de matemáticas é a possibilidade de diminuir bloqueios apresentados por muitos dos nossos alunos que temem a matemática e sentem-se incapacitados para aprendê-la. Dentro da situação de jogos, onde é impossível uma ajuda passiva e a motivação e grande, notamos que, ao mesmo tempo em este alunos falam matemática, apresentam também um melhor desempenho e atitudes mais positivas frente a seus processos de aprendizagem (BRENELLI, 1996, p. 23). 
Percebeu-se que os jogos proporcionam, nos alunos, uma melhor compreensão do conteúdo estudado e afirmam, também, que podem interagir com o professor, transformando a sala de aula num ambiente coletivo de ensino-aprendizagem. Ao realizamos a intervenção, percebemos que os alunos participam de forma espontânea e se mostram motivados em sala de aula. Quando perguntamos, aos alunos, sobre a importância da utilização de jogos como estratégia metodológica para o ensinoaprendizagem, mostraram-se favoráveis. Os sujeitos participantes consideram a intervenção importante porque, segundo o aluno A: "facilita aprendizagem e o ajuda pensar, relembrar as operações e o deixa contente com o resultado. Isso o faz gostar da matemática".

O aluno B, por conseguinte, em seu relato, afirma, e, também, enfatiza uma questão fundamental, sendo ela que: "é importante, porque esses jogos são divertidos e podem nos ajudar a compreender mais e melhor as operações matemáticas". O aluno C, por sua vez, também é favorável à metodologia afirmando, para isso, que acredita que: "acho importante porque desenvolve o raciocínio é uma maneira divertida de aprender matemática". A partir dos relatos, podemos perceber, segundo os alunos, que o uso de jogos em sala de aula deve ser frequente, pois possibilita a saída da rotina diária transformando, dessa forma, a sala de aula em um ambiente agradável e divertido, ao mesmo tempo que incentiva os educandos a gostar da Matemática. $\mathrm{Na}$ visão de Morinaga (2003, p. 3).

O uso de jogos tem o objetivo de fazer com que os alunos gostem de aprender Matemática, despertando o interesse do aluno envolvido. $\mathrm{Na}$ atividade com jogos, os alunos passam a ser elementos ativos do seu processo de aprendizagem, vivenciando a construção do saber e deixando de ser um mero ouvinte passivo.

Nessa perspectiva, podemos considerar que os jogos auxiliam o aluno a desenvolver sua autonomia, favorecem a cooperação, especialmente quando os alunos trabalham em grupos, desenvolvem o raciocínio lógico, potencializando a capacidade de compreensão e mesmo aqueles que são tímidos ou se sentem incapacitados de interpretar e os discentes passam a defender seu ponto de vista, principalmente 
porque todos que jogam querem ganhar. Para Dante (1999, pp. 11-12): "é preciso desenvolver no aluno habilidade de elaborar um raciocínio logico e fazer o uso inteligente e eficaz dos resumos disponíveis, para que ele possa propor boas soluções as questões que surgem no seu cotidiano, na escola ou fora dela". Ao iniciar a aula de intervenção, fez-se uma breve revisão das operações, e, em seguida, apresentouse, aos alunos, o jogo Dominó dos números inteiros, tendo como objetivo expressar os cálculos das operações nos números inteiros e verificar a fixação dos conteúdos.

Assim sendo, ao dar início atividade, explicou-se as regras do jogo Dominó dos números inteiros. Ele segue as mesmas regras do dominó tradicional que contém 28 pedras, ou seja, em cada grupo pode-se jogar com 2, 3 ou 4 alunos. Se o grupo for composto por 2 alunos, cada aluo ficará com 7 pedras e 14 ficarão no monte e poderão ser compradas por uma vez, caso o aluno não tenha pedra para jogar. Assim seguem as regras para o grupo que constituir 3 alunos. No grupo com 4 alunos não teremos o monte e a pedra para jogar, isto é, ele passará a vez (Figura 1). Cada pedra do jogo dominó dos números inteiros continha operações e respostas, cuja uma determinada pedra deveria ser combinada com a outra já posta sobre a mesa. Trabalhamos em sala de aula com 28 alunos divididos em 7 grupos e cada grupo conteve 4 alunos. 
Figura 1 - Jogo do Dominó dos números inteiros

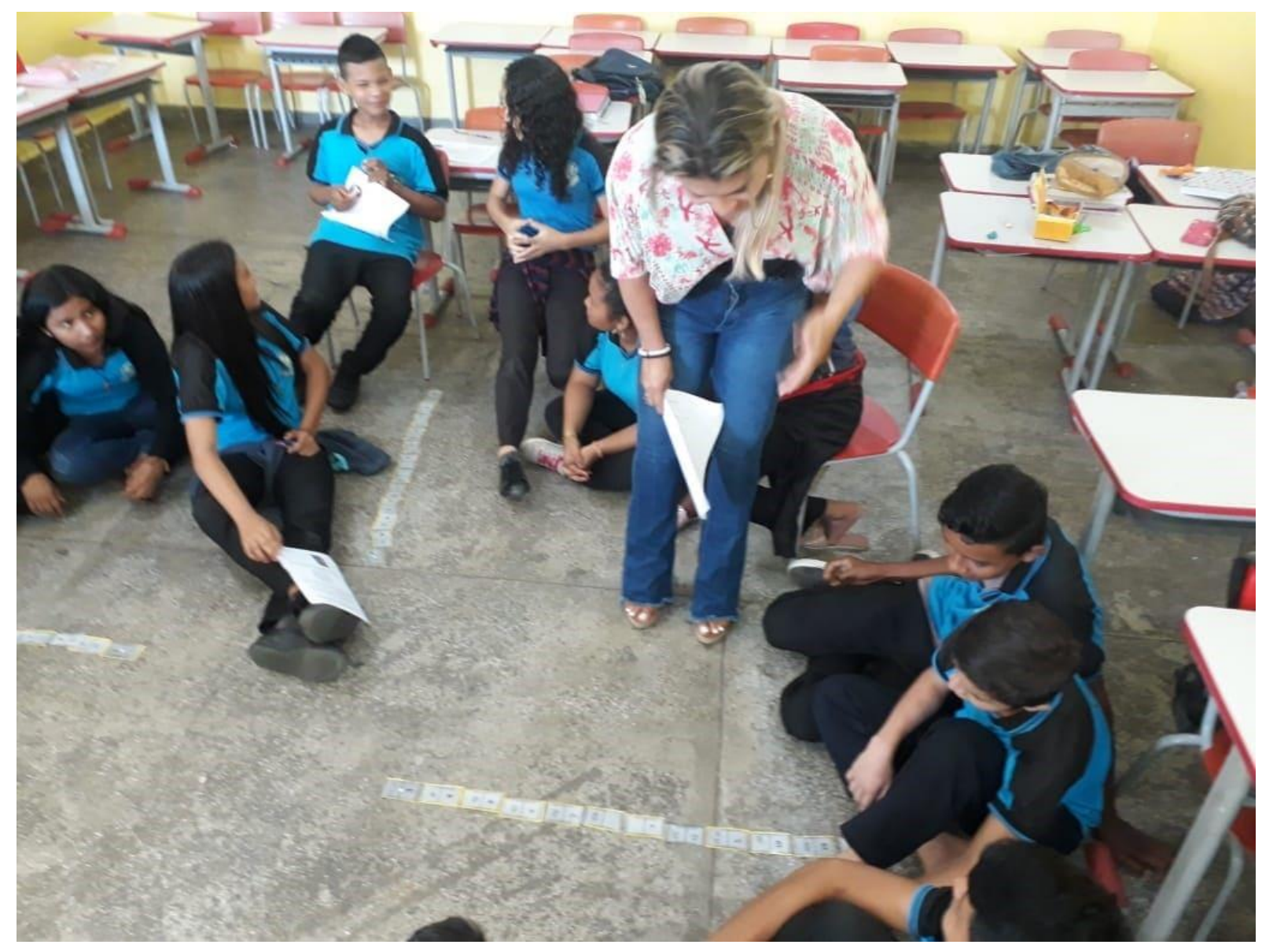

Fonte: Oliveira (2019)

Os alunos foram receptivos quanto ao jogo e todos participaram da atividade realizando as operações a partir do cálculo mental e discutindo como chegar ao resultado entre os membros do grupo. Durante a aplicação do jogo, foi percebido que a turma apresentou dúvidas acerca das operações de sinais, principalmente quando essas operações resultavam em sinais diferentes. Porém, como o jogo educativo também tem a função de socializar, os alunos não se intimidaram em fazer perguntas quando surgiram dúvidas (Figura 2). 
Figura 2: Realização do jogo do Dominó dos números inteiros

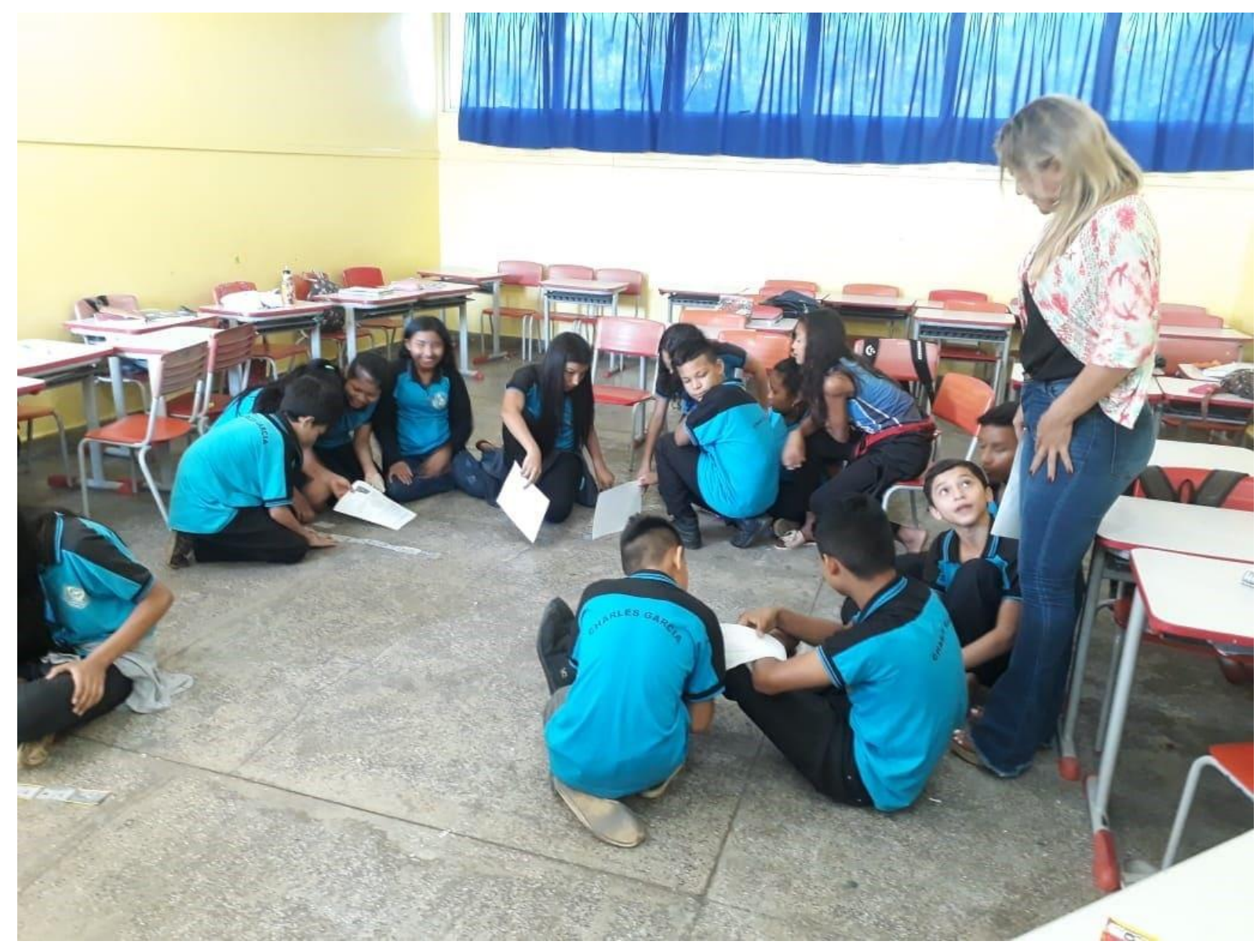

Fonte: Oliveira (2019)

Para fixar os conteúdos, o jogo foi realizado várias vezes obtendo, então, um resultado significativo, conforme percebeu-se na análise das respostas dos alunos sobre o jogo. Eles afirmam que o jogo contribuiu para esclarecer as dúvidas em relação as operações. O aluno D citou: "O dominó dos números inteiros contribuiu muito nos ajudando com as dúvidas e a superar as dificuldades". O aluno e concorda com a utilização do jogo: "sim, porque ele nos faz prestar bastante atenção nos sinais, pois é onde mais erramos e também ninguém quer perder o jogo então, todos jogam pra valer. $O$ aluno $G$ finalizou ressaltando que "tem tudo a ver com a aula porque é importante para todos e nos ajudou bastante". Para obter bons resultados, os professores precisam conhecer, experimentar e adaptar os jogos de acordo com o conteúdo abordado em ala de aula e a necessidade de cada aluno, e, ainda, devem usar de outras formas de acordo com tais especificidades. 
Realizar o mesmo jogo várias vezes, para que o aluno tenha tempo de aprender as regras e obter conhecimentos matemáticos com esse jogo; Incentivar os alunos na leitura, interpretação e discussão das regras do jogo; Propor os registros da jogada ou estratégias utilizadas no jogo; Propor que os alunos criem novos jogos, utilizando os conteúdos estudados nos jogos que ele participou (SMOLE; DNIZ; MILANI, 2007, p. 12).

Dessa forma, entende-se que trabalhar com jogos, de maneira geral, como alternativa metodológica, favorece o processo de ensino-aprendizagem de noções matemáticas, pois, os educandos, são estimulados e incentivados a estudar Matemática, e, assim, a abordagem deixa as aulas mais criativas e desafiadoras. Nas atividades voltadas à aplicação do jogo, torna-se necessário que o professor tenha bom senso para conduzir as atividades de forma tranquila, e, assim, todos devem ser participantes voluntários e devem receber a atenção necessária. Para Freire (1997, p. 96):

O bom professor é que consegue, enquanto fala trazer o aluno até a intimidade do movimento de seu pensamento. Sua aula é assim um desafio e não uma "cantiga de ninar". Seus alunos cansam, não dormem. Cansam porque as idas e vindas de seu pensamento, surpreendem suas pausas, suas dúvidas, suas incertezas.

De acordo com o autor, o professor, ao desenvolver as aulas de forma dinâmica e participativa, deve usar seu conhecimento e experiência. Assim, percebemos, na participação dos alunos, que houve melhoria acerca do entendimento do conteúdo. Desse modo, cabe, ao educador, utilizar, da melhor forma, em sala de aula, o jogo mencionado e outros disponíveis e descobrir o quanto eles podem se tornar recursos eficazes, pois atuam como estratégias metodológicas de ensino-aprendizagem eficiente para a compreensão dos números inteiros. 


\section{CONSIDERAÇÕES FINAIS}

O trabalho buscou mostrar os resultados acerca da utilização do jogo Dominó dos números inteiros como estratégia metodológica para o processo de ensinoaprendizagem nas aulas de Matemática de uma turma do $7^{\circ}$ ano "1" da Escola Municipal Charles Garcia. Como os resultados obtidos foram satisfatórios, sugere-se a utilização de jogos educativos de modo geral, pois foi comprovada a sua importância no processo de ensino-aprendizagem. Durante a intervenção, percebeu-se que os alunos se mostraram bastante interessados em participar das atividades, o que trouxe resultados significativos para o entendimento dos conceitos abordados e devidamente fundamentados por teóricos que defendem a utilização de jogos como estratégia metodológica no intuito de contribuir para com o processo de ensino-aprendizagem de números inteiros. Portanto, espera-se que os resultados obtidos possam motivar os educadores para que estes utilizem os jogos como estratégia metodológica, tornando as aulas de Matemática mais participativas e interessantes aos alunos e, dessa forma, a utilização dos jogos se tornará constante na prática educativa diária, contribuindo, então, para com uma formação cidadã.

\section{REFERÊNCIAS}

BRASIL. Secretaria de Educação Fundamental. Parâmetros Curriculares Nacionais: Matemática/ Secretaria de educação. Brasília: MEC/SEF, 1998.

BRENELLI, R. P. O jogo como espaço para pensar. A construção de noções lógicas e aritméticas. Campinas: Papirus, 1996.

DANT, L. R. Didática da resolução de problemas de matemática. São Paulo: Ática, 1999 .

D'AMBROSIO, U. Desafios da educação Matemática e o novo milênio. São Paulo: Ática, 2001.

FREIRE, P. Pedagogia da Autonomia: saberes necessários à prática educativa. São Paulo: Paz e Terra, 1997. 
FLEMMING, D. M.; MELLO, A. C. C. de. Criatividade e jogos didáticos. São Paulo: Saint Germain, 2003.

GROENWALD, C. L. O.; TIMM, U. T. Utilizando curiosidades e jogos matemáticos em sala de aula. Educação Matemática em Revista, v. 15, n. 2, p. 21-26, 2000.

LAKATOS, E. M. Fundamentos de Metodologia Cientifica 6a . ed. 4a ${ }^{\mathrm{a}}$. Reimpr. São Paulo: Atlas, 2005.

LARA, I. C. M. de. Jogando com a Matemática de $5^{\circ}$ a $8^{\circ}$ série. São Paulo: Respel, 2003.

MOREIRA, H.; CALEFFE, L. G. Metodologia da Pesquisa para o professor pesquisador. 2ª ed. Rio de Janeiro: Lamparina, 2008.

Enviado: Outubro, 2019.

Aprovado: Março, 2020. 